\title{
Effect of Tamsulosin Use on Plasma Insulin Status in Benign Prostatic Hyperplasia Patients in Sokoto, Nigeria
}

\section{${ }^{1}$ DIKKO, M; ${ }^{2}$ BELLO, SO; ${ }^{2}$ CHIKA, A; ${ }^{3}$ MUNGADI, IA; ${ }^{4 *}$ SARKINGOBIR, Y; ${ }^{5}$ UMAR, AI}

\author{
${ }^{I}$ Department of Pharmacy, Sultan Abdurrahman School of Health Technology Gwadabawa, Sokoto state, Nigeria. \\ ${ }^{2}$ Department of Pharmacology and Therapeutics, Usmanu Danfodiyo University Sokoto, Nigeria \\ ${ }^{3}$ Urology Unit, Department of Surgery, Usmanu Danfodiyo University Teaching Hospital Sokoto, Usmanu Danfodiyo University Sokoto, \\ Sokoto state, Nigeria \\ ${ }^{4}$ Department of Biology, Shehu Shagari College of Education Sokoto, Sokoto state, Nigeria \\ ${ }^{5}$ Department of Biochemistry Sokoto State University, Sokoto, Sokoto state, Nigeria \\ *Corresponding Author Email: superoxidedismutase594@gmail.com; Tel: +2348135420062
}

\begin{abstract}
The objective of this paper was to determine the effect of tamsulosin use on plasma insulin status in benign prostatic hyperplasia (BPH) patients in Sokoto, Nigeria. Standard methods and procedures were used. At $2^{\text {nd }}$ and $3^{\text {rd }}$ months of tamsulosin use, there was a significant increase $(\mathrm{P}<0.05)$ in plasma insulin values compared to baseline. Likewise, at $4^{\text {th }}$ month of tamsulosin use, a significant increase $(\mathrm{P}<0.05)$ in plasma insulin values was revealed compared to baseline and $2^{\text {nd }}$ month values. Other inter-mean values comparisons were not significantly different $(\mathrm{P}>0.05)$. Plasma insulin at $4^{\text {th }}$ months of the study in BPH patients (45-54 years) treated with tamsulosin revealed a significant increase $(\mathrm{P}<0.05)$ compared to baseline values. Other inter-mean values comparisons were not significantly different $(\mathrm{P}>0.05)$. $\mathrm{BPH}$ patients (aged 55-64 years) at $3^{\text {rd }}$ month showed a significant increase $(\mathrm{P}<0.05)$ in plasma insulin values compared to baseline values. Likewise, at $4^{\text {th }}$ month of tamsulosin use, a significant increase $(\mathrm{P}<0.05)$ in plasma insulin values was seen compared to baseline and $1^{\text {st }}$ month values. Other inter-mean values comparisons were not significantly different $(\mathrm{P}>0.05)$. In $\mathrm{BPH}$ patients aged 65 and above, there was no significant difference $(\mathrm{P}>0.05)$ in plasma insulin values from $1^{\text {st }}$ through $4^{\text {th }}$ month compared to baseline and other inter mean values comparisons. Plasma insulin at $0^{\text {th }}, 1^{\text {st }}, 2^{\text {nd }}, 3^{\text {rd }}$ and $4^{\text {th }}$ months of BPH patients of different age groups treated with tamsulosin revealed no significant differences $(\mathrm{P}>0.05)$. This study revealed that tamsulosin use in the patients lead to significant increase in plasma insulin level (hyperinsulinemia). Careful and routine monitoring of BPH patients should be done. Patients need enough exercise activities and some drugs can be administered to alleviate elevated glucose or insulin.
\end{abstract}

DOI: $\underline{\text { https://dx.doi.org/10.4314/jasem.v24i4.1 }}$

Copyright: Copyright $\left({ }^{\circ} 2020\right.$ Dikko et al. This is an open access article distributed under the Creative Commons Attribution License (CCL), which permits unrestricted use, distribution, and reproduction in any medium, provided the original work is properly cited.

Dates: Received: 07 February 2020; Revised: 19 March 2020; Accepted: 25 March 2020

Keywords: Tamsulosin, hyperinsulinemia, benign prostatic hyperplasia patients, insulin resistance

Presently, benign prostatic hyperplasia $(\mathrm{BPH})$ and associated lower urinary tract symptoms (LUTs) constitute a prevalent public health threat among older men in Nigeria. To address the BPH and LUTS, a drug called tamsulosin is widely utilized. Tamsulosin is an alpha-1 adrenoreceptors blocker (Muhammad et al., 2007; Dikko, 2019). As tamsulosin is increasingly accepted, adverse drug reaction (ADRs) are emerging due to its usage (Lyseng-Williamson et al., 2002; Kang et al., 2009; Cooney et al., 2012; Dankner et al., 2012). These ADRs include skin rash, respiratory symptoms, constipation, vomiting, and visual problems; which are associated with hyperglycemia or hyperinsulinemia (Dikko, 2019). These are reported in people with hyperglycemia or diabetes (Usman and Mohammed, 2015; Abubakar et al., 2016). Diabetes is a condition defined by the level of hyperglycemia which inturn give rise to microvascular threats (such as nephropathy, neuropathy) and macrovascular problems (such as stroke, peripheral vascular disease, ischaemic heart disease). It is associated with significant morbidity, mortality and reduced quality of life (WHO, 2006). Hypersinsulinemia is a condition in type 2 diabetes stirred by hyperinsulinemia. Dikko (2019) reported hyperglycaemia due to tamsulosin usage in both rats and $\mathrm{BPH}$ patients. Thus, the objective of this paper was to determine the effect of tamsulosin use on plasma insulin status in benign prostatic hyperplasia (BPH) patients in Sokoto, Nigeria.

\section{MATERIALS AND METHODS}

Ethical approval: Ethical approval dated $10^{\text {th July, }}$ 2017 with reference number (UDUTH/HREC/2017/No. 589) was obtained from the Research Ethics Committee of the Usmanu 
Danfodiyo University Teaching Hospital (UDUTH), Sokoto.

Study setting: The study was carried out between August 2017 and July 2018 at the Institute of Urology and Nephrology of Usmanu Danfodiyo University Teaching Hospital (UDUTH), a tertiary hospital situated in Sokoto, a city in the North-Western Nigeria.

Study population: The study population comprised only male subjects diagnosed with benign prostatic hyperplasia (BPH) who indicated for medical treatment that attended the Institute during the period of the study.

Eligibility criteria: The eligibility criteria involved: Patients freshly diagnosed with BPH who indicated for medical treatment that attended the Institute of Urology and Nephrology of the hospital.

BPH patients who gave their consent.

Sampling technique: BPH patients who satisfied the inclusion criteria were selected by convenient sampling. Thirty (30) BPH patients (age, $\geq 45$ years) were consented to be involved in the study. Two (2) patients withdrawn later for personal reasons; whereas, twenty-eight (28) patients completed the study.

Study design: Selected patients were asked to fast overnight (10pm-10am) and report back in the morning to serve as baselines. Soon after that, thirty (30) tamsulosin capsules were given to each patient and sought to take one (1) capsule daily (30 minutes after meal) for a period of one (1) month starting on the day given. The patients were asked not to crush, but rather swallow the capsule and if a dose missed, it should be taken as soon as it was remembered. If missed for the whole day, the next dose should continue on a regular schedule. Similarly, each day they were reminded (through their mobile numbers) to take the drug. At the $30^{\text {th }}$ day, they were asked to fast overnight (10pm-10am) and come back to the institute for the collection of another tamsulosin capsules and analysis of the same parameters (Dikko, 2019).

Determination of plasma insulin of BPH patients treated with tamsulosin: Plasma insulin was determined at baseline and then at $1^{\text {st }}, 2^{\text {nd }}, 3^{\text {rd }}$ and $4^{\text {th }}$ completed months of the study. $1 \mathrm{ml}$ of the blood sample was collected using $2 \mathrm{ml}$ syringe by venous puncture method (after fasting period of 12 hours). Blood immediately was put into chilled heparinized tubes placed on ice. The tubes were then centrifuged using the centrifuging machine at 7000rpm for 5 minutes to collect plasma. Human insulin ELISA kit used to assay the plasma insulin. ELISA method was based on the direct technique in which two monoclonal antibodies were directed against separate insulin antigenic determinant molecule. During incubation, insulin in the sample reacted with antiinsulin antibodies bound to the microtitration well and with peroxidase-conjugated anti-insulin antibodies. During washing, unbound enzyme-labeled antibody was removed while the bound conjugated enzyme was detected and read at a wavelength of $450 \mathrm{~nm}$ using a spectrophotometer. Human insulin standard curve was plotted-using Graphpad (Dikko, 2019).

Statistical Analysis: All results were expressed as Mean \pm SEM. Differences between groups were estimated using either Student t-test or Analysis of Variance (ANOVA). For multiple comparisons, Tukey Kramer post hoc test was used. All calculations and graphs were done using GraphPad prism 7.04 version. The significant level was set at $95 \%(\mathrm{P}<0.05)$ confidence interval.

\section{RESULTS AND DISCUSSIONS}

Plasma insulin at baseline $\left(0^{\text {th }}\right)$ and at $1^{\text {st }}, 2^{\text {nd }}, 3^{\text {rd }}$ and $4^{\text {th }}$ months of the study in benign prostatic hyperplasia patients treated with tamsulosin: At $2^{\text {nd }}$ and $3^{\text {rd }}$ month of tamsulosin use, there was a significant increase $(\mathrm{P}<0.05)$ in plasma insulin values compared to baseline values (Fig. 1). Similarly, at $4^{\text {th }}$ month of tamsulosin use, a significant increase $(\mathrm{P}<0.05)$ in plasma insulin values was seen compared to baseline and $2^{\text {nd }}$ month values (Fig. 1). Other inter-mean values comparisons were not significantly different $(\mathrm{P}>0.05)$.

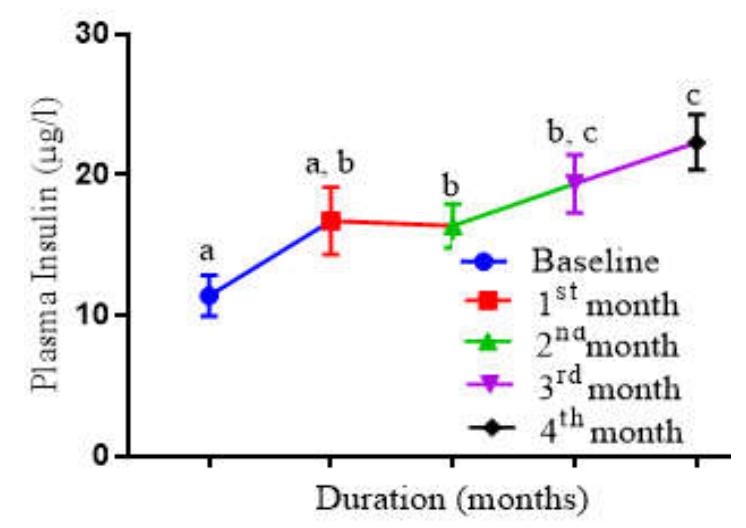

Fig 1: Effect of tamsulosin on plasma insulin at baseline $\left(0^{\text {th }}\right)$ and at $1^{\text {st }}, 2^{\text {nd }}, 3^{\text {rd }}$ and $4^{\text {th }}$ month of the study in BPH patient. Each bar represents Mean $(\mu \mathrm{g} / 1) \pm \operatorname{SEM}(\mathrm{n}=28)$. Student t-test was used.Mean values with different lower case letters are significantly different.

Plasma insulin at baseline $\left(0^{\text {th }}\right)$ and at $1^{\text {st }}, 2^{\text {nd }}, 3^{\text {rd }}$ and $4^{\text {th }}$ months of the study in benign prostatic hyperplasia patients (45-54 years) treated with tamsulosin: A 
significant increase $(\mathrm{P}<0.05)$ in plasma insulin was observed at $4^{\text {th }}$ month of the study compared to baseline values (Fig. 2). Other inter-mean values comparisons were not significantly different $(\mathrm{P}>0.05)$.

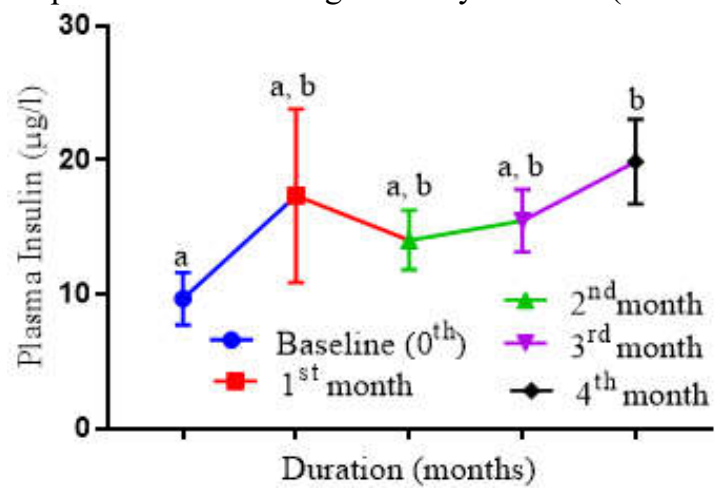

Fig 2: Effect of tamsulosin on plasma insulin at baseline $\left(0^{\text {th }}\right)$ and at $1^{\text {st }}, 2^{\text {nd }}, 3^{\text {rd }}$ and $4^{\text {th }}$ months of the study in BPH patients (45-54 years). Each bar represents Mean \pm SEM $(n=8)$. Student t-test was used. Mean values with different lower case letters are significantly different.

Plasma insulin at baseline $\left(0^{\text {th }}\right)$ and at $1^{\text {st }}, 2^{\text {nd }}, 3^{\text {rd }}$ and $4^{\text {th }}$ months of the study in benign prostatic hyperplasia patients (55-64 years) treated with tamsulosin: At $3^{\text {rd }}$ month of tamsulosin use, there was a significant increase $(\mathrm{P}<0.05)$ in plasma insulin values compared to baseline values (Fig. 3). So also at $4^{\text {th }}$ month of tamsulosin use, a significant increase $(\mathrm{P}<0.05)$ in plasma insulin values was seen compared to baseline and $1^{\text {st }}$ month values (Fig. 3). Other inter-mean values comparisons were not significantly different $(\mathrm{P}>0.05)$.

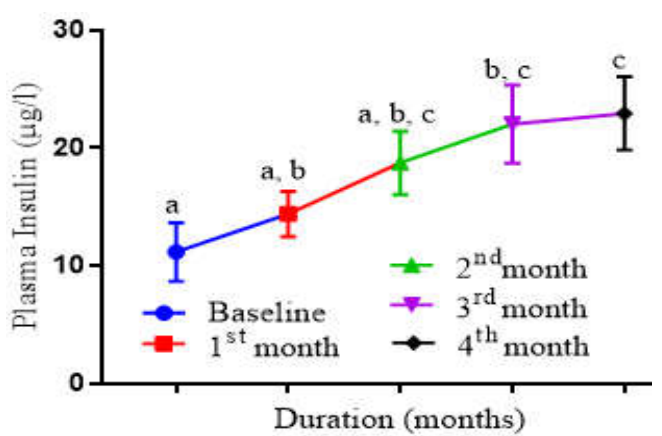

Fig 3: Effect of tamsulosin on plasma insulin at baseline $\left(0^{\text {th }}\right)$ and at $1^{\text {st }}, 2^{\text {nd }}, 3^{\text {rd }}$ and $4^{\text {th }}$ month of the study in BPH patients (55-64 years). Each bar represents Mean \pm SEM $(n=12)$. Student t-test was used. Mean values with different lower case letters are significantly different.

Plasma insulin at baseline $\left(0^{\text {th }}\right)$ and at $1^{\text {st }}, 2^{\text {nd }}, 3^{\text {rd }}$ and $4^{\text {th }}$ months of the study in benign prostatic hyperplasia patients $(65+$ years $)$ treated with tamsulosin: There was no significant difference $(\mathrm{P}>0.05)$ in plasma insulin values from $1^{\text {st }}$ to $4^{\text {th }}$ months compared to baseline and other inter mean values comparison (Fig. $4)$.

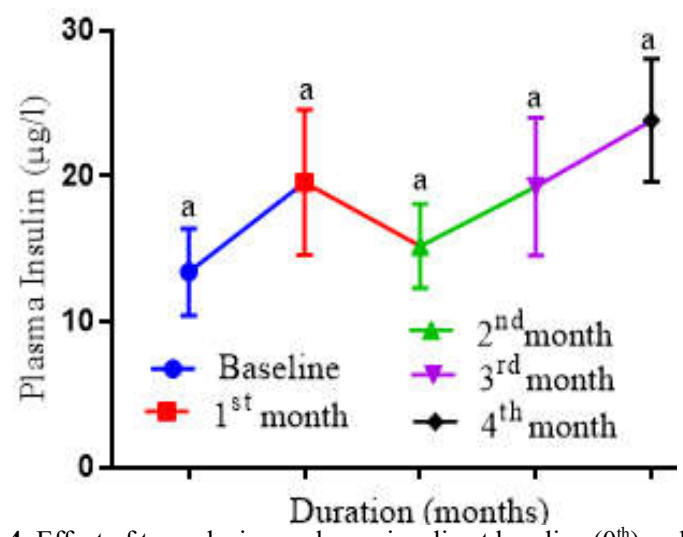

Fig 4: Effect of tamsulosin on plasma insulin at baseline $\left(0^{\text {th }}\right)$ and at $1^{\text {st }}, 2^{\text {nd }}, 3^{\text {rd }}$ and $4^{\text {th }}$ months of the study in BPH patients ( $65+$ years $)$. Each bar represents Mean \pm SEM $(n=8)$. Student t-test was used. Mean values with same lower case letters are not significantly different.

Plasma insulin at baseline $\left(0^{\text {th }}\right)$ of benign prostatic hyperplasia patients of different age groups treated with tamsulosin: At baseline, there were no significant differences $(\mathrm{P}>0.05)$ in the plasma insulin values between the three (3) age groups (Fig. 5).

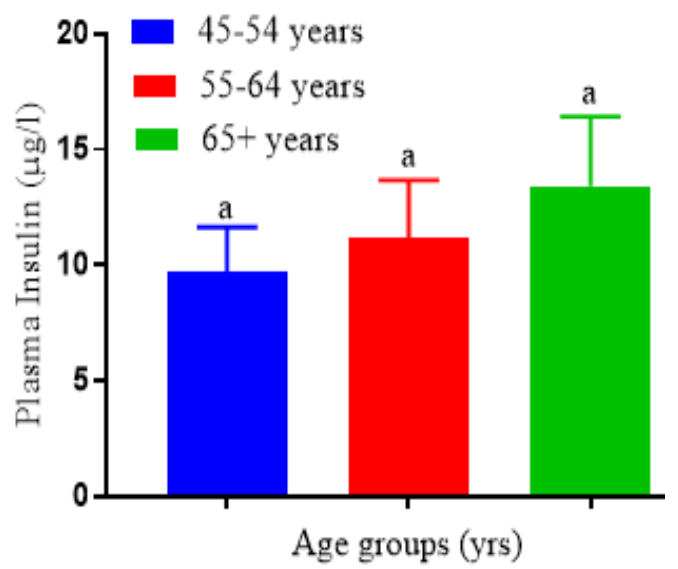

Fig 5: Effect of tamsulosin on plasma insulin at baseline $\left(0^{\text {th }}\right)$ in benign prostatic hyperplasia patients of different age groups. Each bar represents Mean + SEM. ANOVA was used followed by

Tukey Kramer post hoc test. Group with same lower case letters are not significantly different.

Plasma insulin at $1^{\text {st }}$ month of the study in benign prostatic hyperplasia patients of different age groups treated with tamsulosin: At $1^{\text {st }}$ month of the study, there were no significant differences $(\mathrm{P}>0.05)$ in plasma insulin between the three (3) age groups (Fig. $6)$.

Plasma insulin at $2^{\text {nd }}$ month of the study in benign prostatic hyperplasia patients of different age groups treated with tamsulosin: At $2^{\text {nd }}$ month of the study, there were no significant differences $(\mathrm{P}>0.05)$ in plasma insulin values between the three (3) age groups (Figure 7). 


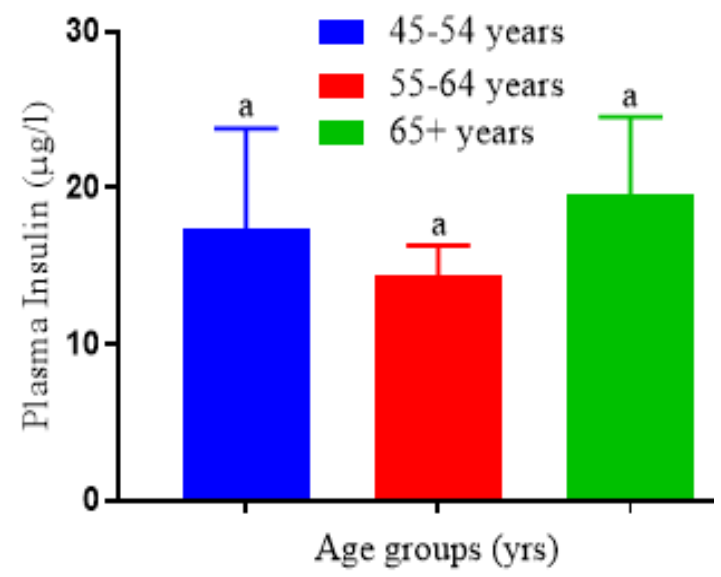

Fig 6: Effect of tamsulosin on plasma insulin at $1^{\text {st }}$ month of the study in BPH patients of different age groups. Each bar represents Mean \pm SEM. ANOVA was used followed by Tukey Kramer post hoc test. Group with same lower case letters are not significantly different.

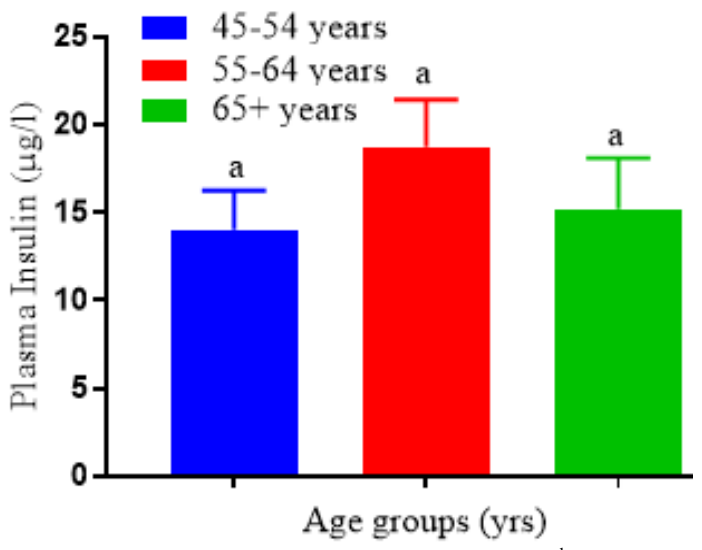

Fig 7: Effect of tamsulosin on plasma insulin at $2^{\text {nd }}$ month of the study of BPH patients of different age groups. Each bar represents Mean \pm SEM. ANOVA was used followed by Tukey Kramer post hoc test. Group with same lower case letters are not significantly different.

Plasma insulin at $3^{\text {rd }}$ month of the study in benign prostatic hyperplasia patients of different age groups treated with tamsulosin: At $3^{\text {rd }}$ month of the study, there were no significant differences $(\mathrm{P}>0.05)$ in plasma insulin values between the three (3) age groups (Fig. 8).

Plasma insulin at $4^{\text {th }}$ month of the study in benign prostatic hyperplasia patients of different age groups treated with tamsulosin: At $4^{\text {th }}$ month of the study, there were no significant differences $(\mathrm{P}>0.05)$ in plasma insulin values between the three (3) age groups (Fig. 9).

This study revealed that tamsulosin use in the patients lead to significant increase in plasma insulin level (hyperinsulinemia). Many mechanisms that might be responsible for this effect were stated. Ideally, elevated insulin level lead to more insulin release.

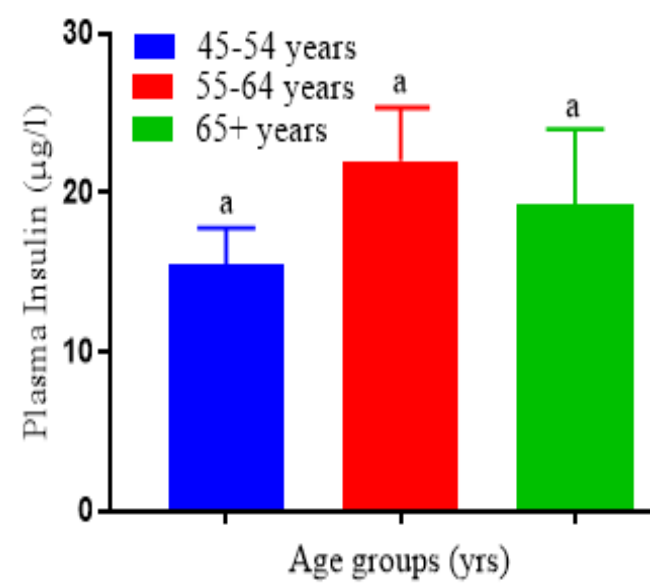

Fig 8: Effect of tamsulosin on plasma insulin at $3^{\text {rd }}$ month of the study in BPH patients of different age groups. Each bar represents Mean \pm SEM. ANOVA was used followed by Tukey Kramer post hoc test. Group with same lower case letters are not significantly different.

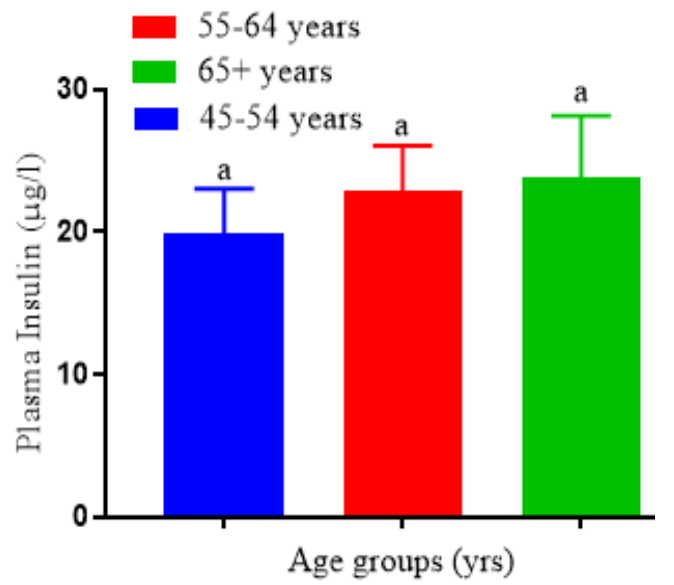

Fig 9: Effect of tamsulosin on plasma insulin at $4^{\text {th }}$ month of the studyin BPH patients of different age groups. Each bar represents Mean \pm SEM. ANOVA was used followed by Tukey Kramer post hoc test.Group with same lower case letters are not significantly different.

In further time, the hyperinsulinemia could occur. One study reported that tamsulosin as an alpha-1 adrenoceptors lead to impairment in glucose homeostasis or hyperglycaemia, which inturn cause hyperinsulinemia (Ahrén et al., 2008). It was documented that hyperinsulinemias are among the risk factors for the development of insulin resistance (Ducluzeau et al., 2002). Insulin resistance refers to the inability of insulin to promote normal cellular glucose uptake at a given insulin concentration. During insulin resistance, pancreatic beta-cells continue to secrete more and more insulin in response to the rising level of blood glucose which eventually leads to the development of hyperinsulinemia (Siddiqui et al., 2013). Others possible mechanisms are increased liver gluconeogenesis and decrease in the skeletal muscle or liver uptake of blood glucose 
(Lee and Halter, 2017). Consequently, the talmusolin persistent use can cause type 2 diabetes if care is not taken. There are some drugs that causes type 2 diabetes mellitus (American Diabetes Association, 2008 Han et al., 2016). Type 2 diabetes remained prevalent among older people like those with BPH. Based on the results of this study tamsulosin lead to increased plasma insulin. These effects portend diabetes (Isa et al., 2013; Muhammad et al., 2015; Abubakar et al., 2016; ). The increase in glucose level instigate an increase in insulin release by the beta-cells of the pancreas; the persistent increased insulin level show that the insulin has a lesion in its normal mechanism of action, hence the continuous elevated status. And high insulin level coupled with high glucose occur in type 2 diabetes mellitus (type 2 DMM).Type 2 DMM is more prevalent among adults. Therefore, the use of tamsulosin in older men could easily predispose them to diabetes mellitus (especially the type 2). Presently, diabetes remains a huge metabolic derangement threatening public health worldwide. It causes much morbidity, death, health spending, and reduced life expectancy of its patients (Wali et al., 2011; Isa et al., 2013; Usman et al., 2015; Marcovecchio, 2017).Thus, this ADR recorded by tamsulosin could be a factor that may discourage its continuous use in the Benign prostate hyplasia (BPH) chemotherapy (Umar et al., 2010; Umar et al., 2016). There is need to give more monitoring and supervision unto people who use tamsulosin.BPH patient taking tamsulosin should be active in exercise, and some drugs can be used concurrently to redress hyperglycemia or hyperinsulinemia otherwise chronic use can lead to type 2 diabetes mellitus (American Diabetes Association 2008; American Diabetes Association 2010).

Conclusion: This study revealed that tamsulosin use in the patients lead to significant increase in plasma insulin level (hyperinsulinemia).

\section{REFERENCES}

Abubakar, MK; Wasagu, RSU; Usman, JN; Galadima, LG (2016). Effect of methanol and aqueous leaf extract of Mitracarpas scabrum in alloxan induced diabetic rats. J. Pharma. Phyto. 5(1): 4-7.

Ahrén, B; Lundquist, I; and Järhult, J (2008). Effects of $\alpha 1$-, $\alpha 2$ - and $\beta$-adrenoceptor blockers on insulin secretion in the rat. Acta Endocrinol. 105 (1): 7882.

American Diabetes Association (2008).Definition ands description of diabetes mellitus. Diabetes Care,31(1):S62-S67.
American Diabetes Association (2010). Definition and description of diabetes mellitus.Diabetes Care,31(1):S62-S69.

Dikko, M (2019). Exploration of gross effect of tamsulosin on glucose and insulin kinetics in rats and humans. A PhD thesis submitted to the Posgraduate School Usmanu Danfodiyo University Sokoto, Nigeria.

Ducluzeau, PH; Fletcher, LM; Vidal, H; Laville, M; Tavaré, JM (2002). Molecular mechanisms of insulin-stimulated glucose uptake in adipocytes. Diabetes

Metab. 28 (2): 85-92.

Han, JS; Moth, HJ; Kim, JS; Kim, HI; Kim, CH; Kim, MJ (2016). Anti-tuberculosis treatment-induced insulin autoimmune syndrome. EWHA Medi. J. 39(4): 122-124.

Isa, SA; Ibrahim KG; Abubakar, I(2013).Effect of camel milk supplementation on serum glucose levels,lipid profile, and body weight of alloxan induced diabetic rats. Nig. J. Basic Appli. Sci. 21 (3):187-191.

Kang, H.E., Bae, SK., Yoo M., Lee D.C., Kim YG., Lee M.G. (2009). Interaction between udenafil and tamsulosin in rats: noncompetitive inhibition of tamsulosin metabolism by by udenafil via hepatic CYP3A1/2. Br. J. 156:1009-1018.

Lee, P.G., and Halter, J.B. (2017). The pathophysiology of hyperglycemia in older adults: Clinical considerations. Diabetes Care $\mathbf{4 0}$ (4): 444-452.

Muhammad, AS; Abdulwahab-Ahmed, A; Agwu, NP; Abdullahi, A; Khalid, A; Mungadi, IA(2007). Pattern of presentation and management of benign upper urinary tract obstruction in Sokoto Northwest Nigeria. Savannah J. Medi. Res. Prac.5(2):1-10.

Marcovecchio M.L. (2017). Implications of acute and chronic hyperglycemia. U.S. Endocrinol. 13(01):1-5.

Siddiqui, AA; Siddiqui, SA; Suhail, A; Siddiqui, S; Ahsan, I; Sahu, K (2013). Diabetes: Mechanism, Pathophysiology and Management-A Review | Insight Medical Publishing. Int. J. Drug Dev. Res. 5 (2): 1-23.

Umar, RA; Hassan, SW; Ladan, MJ; Matazu, IK; 
Shehu, B; Shehu, RA; Muhammed, LG; Molabo, FI (2010). Adverse effect associated with administration of antiretroviral drugs (Nevirapine, Lamivudine and Stavudine) to albino rats: Implication for management of patients with HIV/AIDS. Asian J. Biochem. 5(3): 181-187.

Umar, MT; Bello, SO; Chika, A; Oche, OM (2016). Attitude of nurses and pharmacists on adverse drug reactions reporting in selected hospitals in Sokoto. J. Res. Pharm. Prac. 5:219-2121.
Usman, UZ; Mohammed, M (2015).The effect of ethanol extract of African ficus glumosa leaf on liver function in diabetic rats. J. Mol. Pathophy. 4(3): 103-1076.

Wali, U; Jogana, MU; Zarummai, AL; Saidu, Y; (2011). Antioxidant vitamins and trace elements status of diabetics in Sokoto, Nigeria. Nig. J. Basic Appli. Sci., 19(1):130-134.

WHO (2006). Definition and diagnosis of diabetes mellitus and intermediate hyperglycemia. Report of a WHO/IDF consultation. WHO Geneva, Switzerland. 